Article

\title{
Environmental Risk Assessment of Recycled Products of Spent Coppery Etchant in Jiangsu Province, China
}

\author{
Xiaowei Xu (D), Jing Hua, Houhu Zhang, Zehua Zhao*, Yi Wang, Dapeng Zhang, Jun Zhang and Xiaoxi Chen \\ Nanjing Institute of Environmental Science, Ministry of Ecology and Environment of China, \\ Nanjing 210042, China; xuxiaowei@nies.org (X.X.); huajing@nies.org (J.H.); zhh@nies.org (H.Z.); \\ wangyi@nies.org (Y.W.); zhangdapeng@nies.org (D.Z.); zhangjun@nies.org (J.Z.); chenxiaoxi@nies.org (X.C.) \\ * Correspondence: zhaozehua@nies.org
}

Citation: Xu, X.; Hua, J.; Zhang, H.; Zhao, Z.; Wang, Y.; Zhang, D.; Zhang, J.; Chen, X. Environmental Risk Assessment of Recycled Products of Spent Coppery Etchant in Jiangsu Province, China. Int. J. Environ. Res. Public Health 2021, 18, 7881. https:// doi.org/10.3390/ijerph18157881

Academic Editor: Paul B. Tchounwou

Received: 18 June 2021

Accepted: 11 July 2021

Published: 26 July 2021

Publisher's Note: MDPI stays neutral with regard to jurisdictional claims in published maps and institutional affiliations.

Copyright: (c) 2021 by the authors. Licensee MDPI, Basel, Switzerland. This article is an open access article distributed under the terms and conditions of the Creative Commons Attribution (CC BY) license (https:// creativecommons.org/licenses/by/ $4.0 /)$

\begin{abstract}
With the vigorous development of the 5G industry, the characteristic hazardous waste, spent coppery etchant, was also produced in large quantities. In recent years, there are many companies that have begun to collect spent coppery etchant for the purpose of producing recycled products, such as copper sulfate, copper oxide, basic copper chloride, and copper powder, which often contain large amounts of heavy metals. However, due to the lack of relevant standards and applicable regulatory measures, some of the recycled products flow to the feed processing industry and even to the food processing industry. This study investigated the pollution status of heavy metals in recycled products of spent coppery etchant and evaluated the impact of recycled products exposure on human health. The results showed that the content of $\mathrm{Zn}$ was the highest, which was 21 times higher than the corresponding standard limit. Human health risk assessment indicated that the hazard quotients of As account for $87.5 \%$ of the entire HI value, while the average carcinogenic risk values of As for copper sulfate, copper oxide, basic copper chloride, and copper powder are $1.09 \times 10^{-5}, 3.19 \times 10^{-5}, 1.29 \times 10^{-5}, 7.94 \times 10^{-6}$, respectively. Meanwhile, suggestions on the supervision of recycled products and the concentration limits of heavy metals in recycled products were put forward.
\end{abstract}

Keywords: recycled product; spent coppery etchant; environmental risk assessment; heavy metals

\section{Introduction}

With the vigorous development of China's 5G industry, the production capacity of mobile phones, computers, and other electronic products has shown explosive growth [1]. At the same time, the production of spent copper etchant, as a waste fluid from the etching process in the electronic component manufacturing industry, is increasing year by year [2]. It is reported that Jiangsu Province, as one of the most crucial electronic products manufacturing areas in China, produces more than 350,000 tons of spent coppery etchant every year [3]. Spent coppery etchant is a kind of hazardous waste (HW22) listed on the National Hazardous Waste List and usually contains about 10\% copper and other heavy metals in varying amounts, such as zinc, nickel, cadmium, chromium, and arsenic [4].

In recent years, there are numerous companies that have begun to collect spent coppery etchant for the purpose of producing recycled products. Comprehensive utilization methods of spent coppery etchant mainly include a synthetic process, electrolysis process, and replacement process. The synthesis method takes the form of extracting recycled copper products by neutralization of acidic (alkaline) copper that contains etching waste liquor or by a reaction with acid or alkali. The replacement method refers to the process of adding iron powder and aluminum powder into the spent coppery etchant to replace copper ions to produce recycled copper products. The electrolysis method takes the form of producing recycled copper products by electrolysis equipment using spent coppery etchant as raw material. The commonly recycled products are copper sulfate, basic copper carbonate, copper hydroxide, and copper powder. However, due to the limitation of 
production technology and enterprise management levels, these recycled products usually contain heavy metals such as $\mathrm{Zn}, \mathrm{Ni}, \mathrm{Cd}, \mathrm{Cr}$, and $\mathrm{As}$ [5].

At present, these recycled products are sold mainly in accordance with industrial product quality standards, such as Industrial Copper Sulfate (HG/T 5215, 2017), Copper Oxide Powder (GB/T 26046, 2010), Industrial Cuprous Chloride (GB/T 27562, 2011), Crude Copper (YS/T 70, 2005), Industrial Basic Copper Carbonate (HG/T 4825, 2015), Industrial Basic Copper Chloride (HG/T 4826, 2015), and Regenerated Copper Hydroxide (HG/T 4699 , 2014). However, these product quality standards fail to take into account recycled products made from hazardous waste. Thus, they are not fully applicable to recycled products from spent copper etchants.

According to the investigation, the recycled products are used primarily for industrial purposes, including copper smelting raw materials, cables, wood preservatives, fungicides, etc., but some of the recycled products flow to the feed processing industry and even to the food processing industry [5]. Previous studies have established that heavy metals can cause anemia, bronchitis, and even damage to the nervous system [6] through ingestion, inhalation, and dermal contact [7]. For example, cadmium can replace calcium in the bone when it goes into the body, causing severe softening of the bones and also causing dysfunction of human organs [8]. Additionally, acute mercury poisoning can induce hepatitis and hematuria. Inhalation of chromium particles may irritate the respiratory tract and cause laryngitis and bronchitis [9]. As a result, the U.S. EPA has listed some metals as priority pollutants because of their toxicity, bioaccumulation, and low degradability [10].

Once these recycled products enter the feed processing industry or even the food processing industry, the heavy metals in the recycled products may harm human health through ingestion, skin contact, and inhalation. In recent years, some researchers have investigated the human health risks caused by various environmental pollution. However, most of them have concentrated on large-scale and regional pollution research and discussed the risks for large regions [11]. They are often not related to the health risks of specific industries, especially the electronic components manufacturing industry [6]. The output of recycled products from spent coppery etchant is increasing year by year, but its ecological risk is rarely concerned. Therefore, this work used the risk assessment model recommended by the U.S. EPA to investigate and evaluate the heavy metal pollution level of recycled products and estimate the impact of heavy metal exposure on human health.

\section{Materials and Methods}

\subsection{Study Area}

As an important manufacturing area of electronic products in China, the output of spent coppery etchant in Jiangsu Province accounts for $47.5 \%$ of the whole country. So far, there are more than 10 spent coppery etchant comprehensive utilization companies with an approved scale of more than 10,000 tons. In this study, the main recycled products of these large-scale enterprises were collected for detection and analysis.

\subsection{Sample Collection and Analysis}

The common products recovered from spent coppery etchant include mainly copper sulfate, copper oxide, basic copper chloride, and copper powder. In this investigation, 5 samples of each of the above products were collected, and a total of 20 samples of recycled products were collected. Each sample was collected by the quartering method, and each sample was about $2 \mathrm{~kg}$. Then the samples were preserved and transported according to the Technical Specifications on Sampling and Sample Preparation from Industry Solid Waste (HJ/T 20, 1998). Before analysis, samples were air-dried, pulverized (TRM4-1L, Gredeman, Shanghai, China), and sieved (100 mesh).

For the determination of heavy metal content in each sample, $100 \mathrm{mg}$ of completely mixed recycled product was digested with $10 \mathrm{ml}$ of aqua regia and hydrofluoric acid mixture (7:3 v/v) followed by microwave digestion (Mars 5, CEM, Raleigh, NC, USA) [12]. Then, the concentrations of zinc, lead, nickel, cadmium, and chromium in the digestion 
were determined by inductively coupled plasma mass spectrometry (iCAP RQ, Thermo Fisher, Waltham, MA, USA), while mercury and arsenic were determined by atomic fluorescence spectrometry (AFS-8520, Haiguang, Beijing, China) [12,13].

In order to ensure the accuracy and reliability of the experimental data, the reagents used in the experiment are all analytically pure. Parallel samples and blank samples were set for the determination of heavy metals, and the results were within the allowable error range. The detection limits of zinc, nickel, cadmium, lead, chromium, mercury and arsenic in digestion solution were $0.01 \mathrm{mg} / \mathrm{L}, 0.02 \mathrm{mg} / \mathrm{L}, 0.01 \mathrm{mg} / \mathrm{L}, 0.03 \mathrm{mg} / \mathrm{L}, 0.02 \mathrm{mg} / \mathrm{L}$, $0.0002 \mathrm{mg} / \mathrm{L}$, and $0.0001 \mathrm{mg} / \mathrm{L}$, respectively.

\subsection{Comprehensive Index Method}

The comprehensive index method [14] was used to evaluate the heavy metal pollution of recycled products, and the calculation formula used was Equation (1).

$$
P_{i}=\frac{1}{n} \sum C_{i} / S_{i}
$$

where $P$ is the comprehensive index of heavy metals pollution status for recycled products (unitless), C is the concentration of metals in the recycled products ( $\mathrm{mg} / \mathrm{kg}$ ), and $\mathrm{S}$ is the product quality standard value of heavy metals $(\mathrm{mg} / \mathrm{kg})$. Tables 1 and 2 show the product quality standard value and product quality classification respectively.

Table 1. The product quality standard value of heavy metals $(\mathrm{mg} / \mathrm{kg})$.

\begin{tabular}{cc}
\hline Metal & Standard Value $^{\mathbf{1}}$ \\
\hline $\mathrm{Ni}$ & 10 \\
$\mathrm{Cd}$ & 6 \\
$\mathrm{Cr}$ & 30 \\
$\mathrm{As}$ & 20 \\
$\mathrm{~Pb}$ & 5 \\
$\mathrm{Hg}$ & $\mathrm{N} . \mathrm{A}$. \\
$\mathrm{Zn}$ & 20 \\
$\mathrm{Ni}$ & 10 \\
$\mathrm{Cd}$ & 6 \\
\hline
\end{tabular}

${ }^{1}$ The standard values of heavy metals mainly refer to China's national or industrial product quality standards and take the minimum value in each standard. N.A. = Not Available.

Table 2 . The product quality classification.

\begin{tabular}{ccc}
\hline Class & Value & Product Quality \\
\hline 1 & $P \leq 0.7$ & Practically uncontaminated \\
2 & $0.7<P \leq 1$ & Uncontaminated to moderately contaminated \\
3 & $1<P \leq 2$ & Moderately contaminated \\
4 & $2<P \leq 3$ & Moderately to extremely contaminated \\
5 & $P>3$ & Extremely contaminated \\
\hline
\end{tabular}

\subsection{Human Health Risk Assessment}

It is reported that some recycled products have entered the feed processing industry and even the food processing industry, which may endanger human health through inhalation, ingestion, and skin contact. The general exposure equation used in this study is based on recommendations provided by the U.S. EPA. The average daily intake (ADI) can be calculated according to Equations (2)-(4).

$$
\begin{gathered}
\mathrm{ADI}_{\text {ing }}=C \times \frac{\operatorname{Ing} R \times E F \times E D}{B W \times A T} \times 10^{-6} \\
\mathrm{ADI}_{\text {der }}=\mathrm{C} \times \frac{S A \times A F \times A B S \times E F \times E D}{B W \times A T} \times 10^{-6}
\end{gathered}
$$




$$
\mathrm{ADI}_{i n h}=C \times \frac{I n h R \times E F \times E D}{P E F \times B W \times A T}
$$

where ADI_ing, ADI_der, and ADI_inh are the average daily intake from ingestion, inhalation, and dermal absorption respectively ( $\mathrm{mg} / \mathrm{kg}$-day), $\operatorname{Ing} R$ and $\operatorname{InhR}$ are the ingestion and inhalation rate of recycled products respectively ( $\mathrm{mg} /$ day, $\mathrm{m}^{3} /$ day), $B W$ is the bodyweight of the exposed individual $(\mathrm{kg}), P E F$ is the emission factor $\left(\mathrm{m}^{3} / \mathrm{kg}\right), A F$ is the adherence factor ( $\mathrm{mg} / \mathrm{cm}^{2}$-day), $A B S$ is the dermal absorption factor (unitless), $S A$ is the exposed skin surface area $\left(\mathrm{cm}^{2}\right), C$ is the concentration of metals in the recycled products $(\mathrm{mg} / \mathrm{kg}), E D$ is the exposure duration (year), $E F$ is the exposure frequency (day/year), and $A T$ is the time period over which the dose is averaged (day) [15].

For the carcinogenic and non-carcinogenic risks of heavy metals, the carcinogenic risk $(C R)$ can be calculated according to Formula (5). In order to assess the carcinogenic risk posed by more than one chemical and/or multiple pathways, the carcinogenic risk index (CRI) can be determined according to Formula (6). Similarly, Formula (7) can be used to calculate the non-carcinogenic risk index $(\mathrm{HI})$.

$$
\begin{gathered}
C R=A D I \times S F \\
C R I=\sum A D I_{i} \times S F_{i} \\
H I=\sum H Q_{i}=\sum \frac{A D I_{i}}{R f D_{i}}
\end{gathered}
$$

where $S F$ is the slope factor ( $\mathrm{mg} / \mathrm{kg}$-day), $R f D$ is the reference dose $(\mathrm{mg} / \mathrm{kg}$-day) [14].

\section{Results and Discussion}

\subsection{Heavy Metal Contents in Recycled Products}

From Figure 1, the average concentration of each heavy metal in most recycled products exceeds the corresponding product quality standard value. The mean concentrations of $\mathrm{Zn}, \mathrm{Ni}$, and As are about 8.3, 3.2, and 1.1 times greater, respectively than the standard values. For $\mathrm{Zn}$, the content of $\mathrm{Zn}$ in all samples exceeded the standard value, and the maximum content exceeded the standard value by 21 times. The average contents of $\mathrm{Ni}$ and $\mathrm{Cr}$ were less than the standard values, while $\mathrm{Hg}$ and $\mathrm{Cd}$ were not detected. From this analysis, the recycled products were contaminated the most by $\mathrm{Zn}$ and the least by $\mathrm{Cd}$ and $\mathrm{Hg}$.

As shown in Figure 2, among the recycled products, copper sulfate appears to be the least contaminated, with most of the $p$-values below 0.7 . This may be due to the fact that the copper sulfate production process is more conducive to the separation and removal of heavy metals [2]. Meanwhile, basic copper carbonate, copper oxide, and copper powder show the highest $p$-values for heavy metals. The $P$-value of $\mathrm{Zn}$ in basic copper carbonate is as high as 9.27, and that of $\mathrm{Ni}$ is close to 3. Additionally, the $p$-values of $\mathrm{Zn}, \mathrm{Ni}$, and $\mathrm{As}$ in copper oxide are all greater than 2, while the $p$-values of $\mathrm{Zn}$ and $\mathrm{Ni}$ in copper powder are all greater than 5 . It should be noted that the $P$-value of $\mathrm{Zn}$ in all samples of the four recycled products is greater than 2 . 

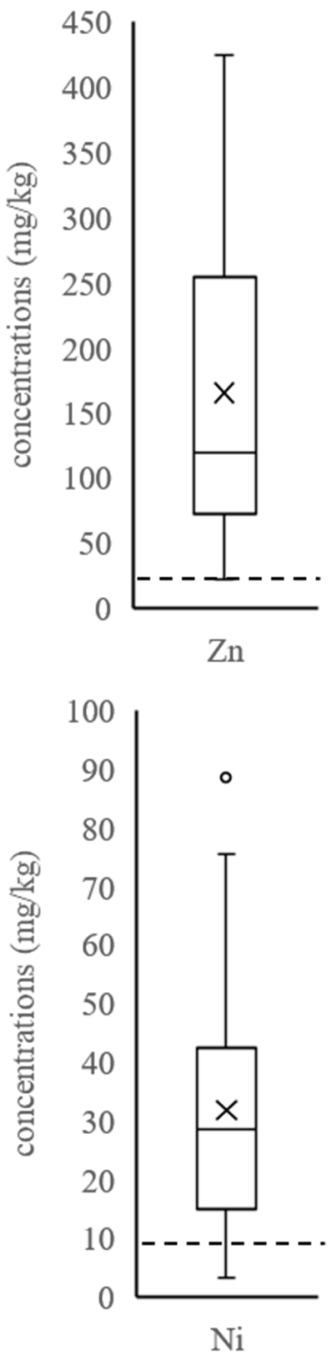
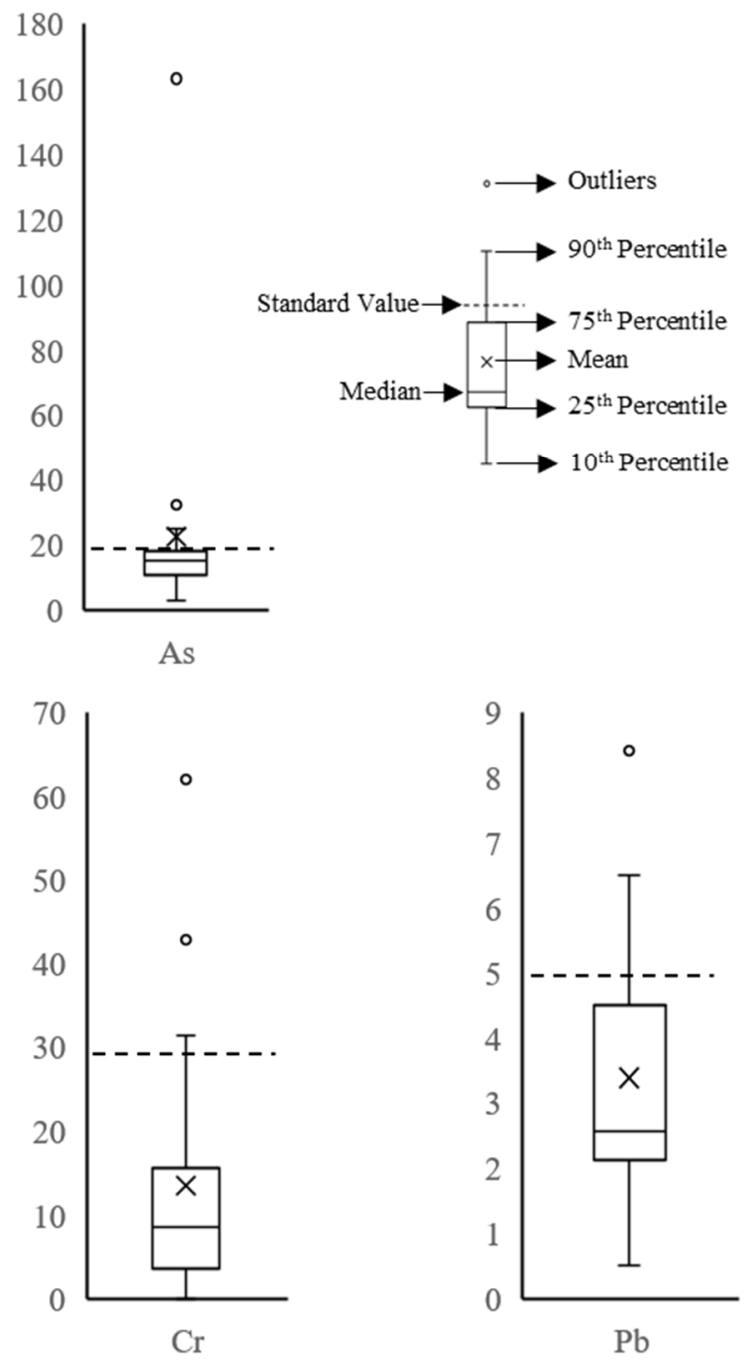

Figure 1. Boxplots of the heavy metal concentrations $(\mathrm{mg} / \mathrm{kg})$ for the recycled products.

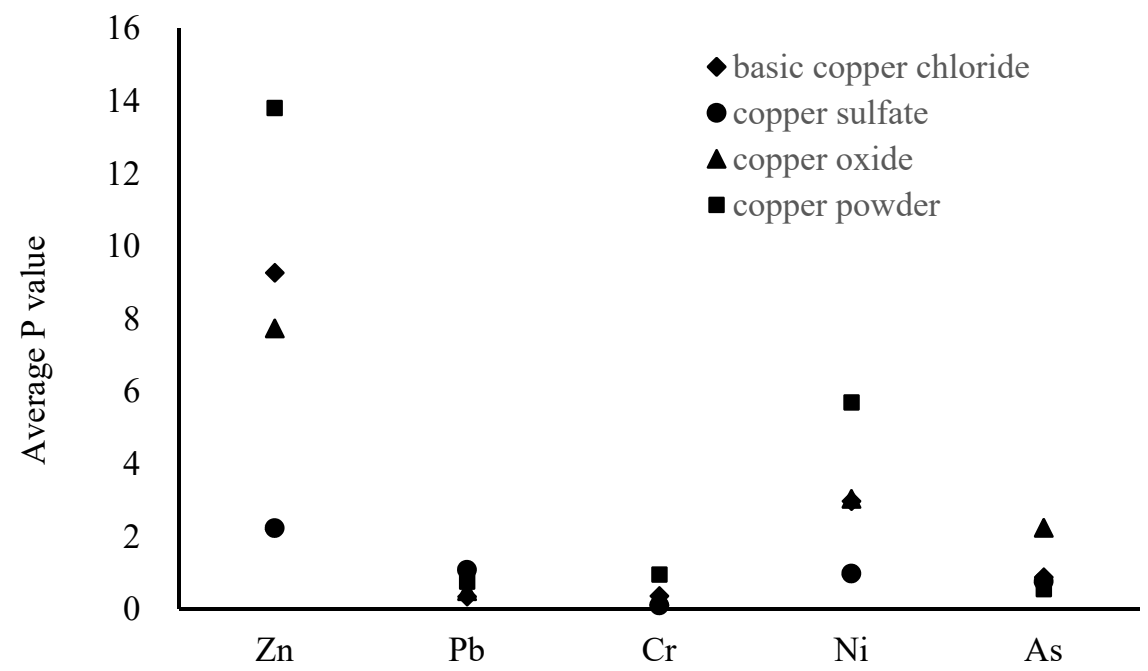

Figure 2. Average $p$-values of heavy metals for different types of recycled products.

Table 3 reveals the class distribution of $p$-values for heavy metals, which was based on the classification system in Table 2 . The results showed that the $p$-values of $\mathrm{Pb}$ in all the recycled products were lower than grade 2 , and nearly $75 \%$ of the products belonged to 
class 1 . More than $85 \%$ of the recycled products were lower than class 1 for $\mathrm{Cr}$. Meanwhile, the $p$-values for $\mathrm{Zn}$ were above class 4 for nearly $95 \%$ of samples. The $p$-values of $\mathrm{Ni}$ and As vary the most, ranging from class 1 to class 5 ; however, the $p$-values of these two elements are mostly lower than class 3 .

Table 3. Class distribution of $p$-value for heavy metals.

\begin{tabular}{cccccc}
\hline Class & Zn & Pb & Cr & Ni & As \\
\hline 1 & $0 \%$ & $65 \%$ & $80 \%$ & $15 \%$ & $40 \%$ \\
2 & $0 \%$ & $15 \%$ & $5 \%$ & $0 \%$ & $40 \%$ \\
3 & $10 \%$ & $20 \%$ & $10 \%$ & $15 \%$ & $15 \%$ \\
4 & $10 \%$ & $0 \%$ & $5 \%$ & $25 \%$ & $0 \%$ \\
5 & $80 \%$ & $0 \%$ & $0 \%$ & $45 \%$ & $5 \%$ \\
\hline
\end{tabular}

As showed in Figure 3, the average $p$-values for $\mathrm{Pb}$ and $\mathrm{Cr}$ were 0.68 and 0.45 , respectively, classifying these two elements as practically uncontaminated. The average $p$-values of as for all recycled products ranged between 1 and 2, indicating that the samples were marked as moderately contaminated. The average $p$-values for $\mathrm{Ni}$ and Zn categorized these metals into class 3 . Overall, the contamination levels of these heavy metals are generally in the order of $\mathrm{Zn}>\mathrm{Ni}>\mathrm{As}>\mathrm{Pb} / \mathrm{Cr}>\mathrm{Hg} / \mathrm{Cd}$.

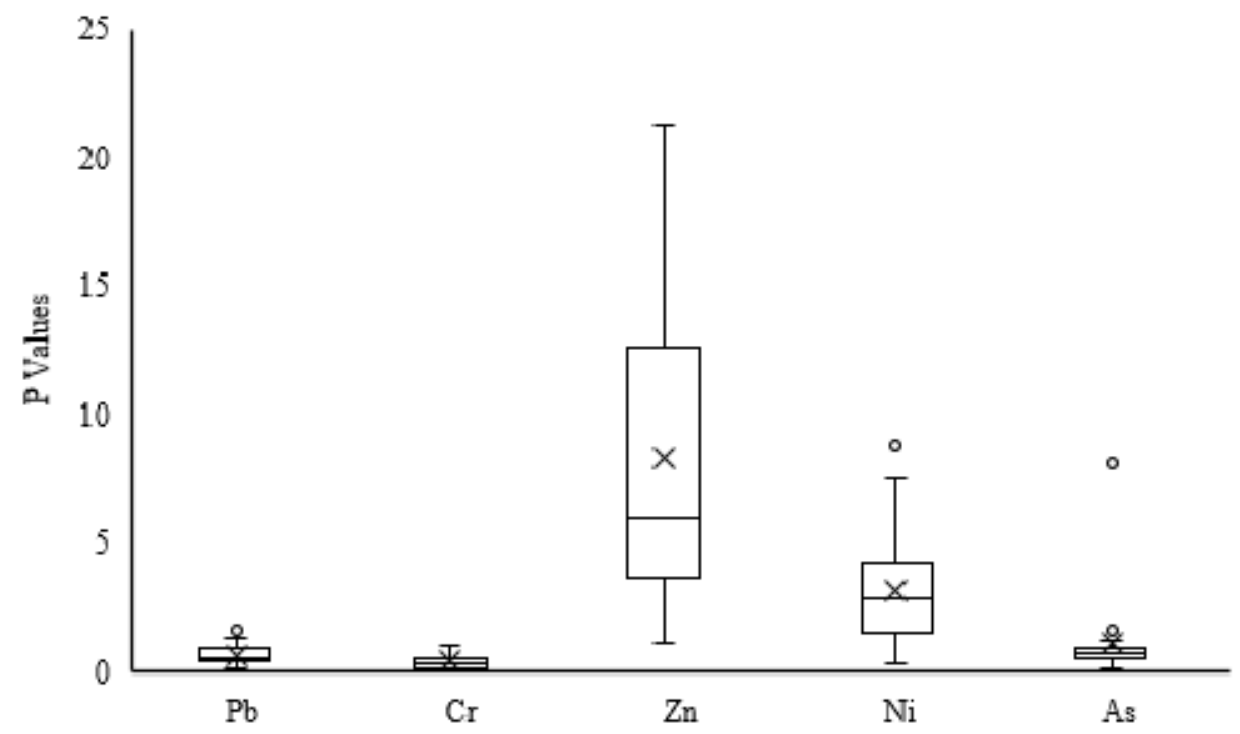

Figure 3. Boxplots of the $p$-values for the heavy metals.

\subsection{Non-Carcinogenic Risk}

Since dermal absorption factors for $\mathrm{Cr}, \mathrm{Pb}, \mathrm{Hg}, \mathrm{Ni}$, and $\mathrm{Zn}$ were not available, the non-carcinogenic hazard index of $\mathrm{Cr}, \mathrm{Pb}, \mathrm{Hg}, \mathrm{Ni}$, and $\mathrm{Zn}$ were calculated from ingestion and inhalation absorption pathways. For non-carcinogenic risks, ingestion-absorption was the primary exposure pathway for $\mathrm{As}, \mathrm{Cd} \mathrm{Cr}, \mathrm{Pb}, \mathrm{Hg}, \mathrm{Ni}$, and $\mathrm{Zn}$. For example, the average daily intake of $\mathrm{Zn}$ through the ingestion absorption pathway for adults reaches levels of $0.024 \mathrm{mg} / \mathrm{kg}$-day, whereas the average daily intake of $\mathrm{Zn}$ through the dermal and inhalation pathway for adults is only $0.0044 \mathrm{mg} / \mathrm{kg}$-day and $0.0002 \mathrm{mg} / \mathrm{kg}$-day respectively.

Of all the heavy metals investigated, people are most exposed to As and Ni due to their high concentrations in the recycled products or low reference doses, while they are least exposed to the remaining heavy metals. For example, the hazard quotients of As and $\mathrm{Ni}$ accounted for $87.5 \%$ and $9.3 \%$ of the entire $\mathrm{HI}$ value, respectively. In comparison, the overall proportion of the remaining heavy metals in the overall $\mathrm{HI}$ was $3.2 \%$. It is worth mentioning that although the $p$-value of $\mathrm{Zn}$ was the highest, the non-carcinogenic environmental risk of $\mathrm{Zn}$ only accounted for $0.3 \%$ of the total risk. 
From Wang et al.'s study [16], if the value of $\mathrm{HI}$ is less than 1, there are no significant adverse health effects; if the value of $\mathrm{HI}$ is greater than 1, non-carcinogenic effects are likely to appear, and the likelihood of such effects increases as the HI value increases. As shown in Figure 4, The HI values of basic copper carbonate, copper sulfate, and copper powder were less than 1 , which indicates that the non-carcinogenic risk of these three recycled products was within the acceptable range. However, the $\mathrm{HI}$ value of some $\mathrm{CuO}$ samples was greater than 1 , which indicates that once the recycled product enters the supply chain, it may pose a threat to human health.

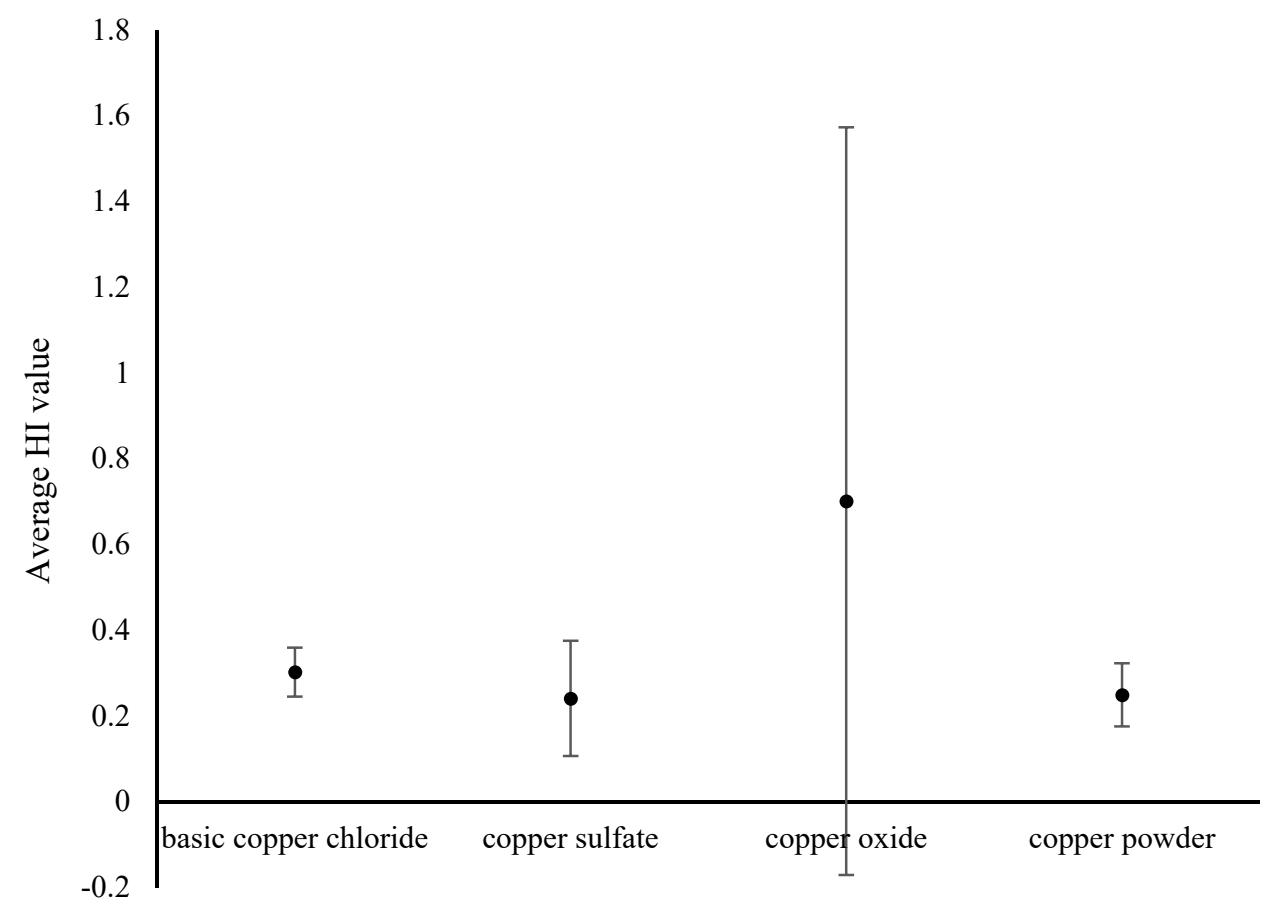

Figure 4. Average HI values ( \pm standard deviation) for different types of the recycled products.

\subsection{Carcinogenic Risk}

Owing to the lack of carcinogenic slope factors for other heavy metals, only the carcinogenic risk of As was assessed. In terms of carcinogenic risk, ingestion absorption is the main exposure pathway for As. The average intake of As by the ingestion absorption route in adults reached a level of $0.0037 \mathrm{mg} / \mathrm{kg}$-day, while the average intake of As by the dermal and inhalation routes in adults was only $0.0007 \mathrm{mg} / \mathrm{kg}$-day and $0.00003 \mathrm{mg} / \mathrm{kg}$-day, respectively. This result was analogous to the findings of a study that examined the health risks of heavy metal contamination in the Daxin manganese mining area [17].

In accordance with the work by Sharafi et al. [18], the acceptable carcinogenic risk index ranges between $10^{-6}$ to $10^{-4}$. It implies that risks of greater than $10^{-4}$ are regarded as being unacceptable, while risks of less than $10^{-6}$ are not perceived as having a substantial undesirable impact. Average As carcinogenic risk values for copper sulfate, copper oxide, basic copper chloride, and copper powder are $1.09 \times 10^{-5}, 3.19 \times 10^{-5}, 1.29 \times 10^{-5}$, $7.94 \times 10^{-6}$, respectively. Therefore, the average carcinogenic risk of these four recycled products was within the acceptable range. However, it is worth noting that the maximum carcinogenic risk of copper oxide was $1.16 \times 10^{-4}$, which is unacceptable.

\section{Recommendation}

The existing product quality standards are obviously not suitable for recycled products of spent coppery etchant. For example, the comprehensive index $p$-value of heavy metal $\mathrm{Zn}$ is generally high, which indicates that the $\mathrm{Zn}$ content in recycled products is significantly higher than the limit value of existing product quality standards. However, the results of the human health risk assessment show that the risk level of $\mathrm{Zn}$ in recycled 
products can be almost negligible. In addition, the As content in some samples is high, which makes the carcinogenic risk and non-carcinogenic risk of these recycled products exceed the acceptable range. However, most product quality standards do not attach importance to As. In addition, $\mathrm{Cd}$ and $\mathrm{Hg}$ were not detected in these recycled products, indicating that $\mathrm{Cd}$ and $\mathrm{Hg}$ are not characteristic pollutants. Meanwhile, among the four common recycled products, copper oxide has the highest $\mathrm{HI}$ value, while copper sulfate has the lowest environmental risk. Therefore, the management department can strengthen the management of copper oxide, or introduce policies to encourage the production of copper sulfate.

To sum up, it is urgent that a standard is established that comprehensively considers the environmental risk and product quality of recycled products from spent coppery etchant. The formulation of standard limits should consider controlling the environmental risk of recycled products, and should not set the requirements too high to increase unnecessary process costs. According to the carcinogenic and non carcinogenic risk assessment, the recommended limited concentrations for $\mathrm{As}, \mathrm{Ni}, \mathrm{Cr}, \mathrm{Pb}$, and $\mathrm{Zn}$ in recycled products are 50-100 mg / kg, 100-300 mg / kg, 50-100 mg / kg, 100-300 mg / kg, 200-500 mg / kg, respectively, and $\mathrm{Cd}$ and $\mathrm{Hg}$ are not required. If these recycled products can be restricted to industrial use by regulatory means, the corresponding concentration limits can be set higher.

\section{Conclusions}

An investigation of heavy metal pollution in recycled products of spent coppery etchant and a human health risk assessment was conducted for this study. The general situation of heavy metal pollution was firstly described. Zn was the highest content component, however, as pollution was the most momentous in recycled products. Human health risk assessment was calculated based on the risk exposure model recommended by the U.S. EPA, and the results indicated that both non-carcinogenic and carcinogenic risks of heavy metals in recycled products were acceptable. In addition, the leaching rate or stability of heavy metals can be considered in evaluating the risk of heavy metals in recycled products. Despite its limitations, we believe this is the first report about information on recycled products in China. This article may provide some evidence and references for future management decisions.

Author Contributions: Conceptualization, J.H.; methodology, H.Z.; software, D.Z.; validation, Y.W. and J.Z.; investigation, X.C.; writing-original draft preparation, X.X.; writing-review and editing Z.Z. All authors have read and agreed to the published version of the manuscript.

Funding: This research received no external funding.

Institutional Review Board Statement: Not applicable.

Informed Consent Statement: Not applicable.

Conflicts of Interest: The authors declare no conflict of interest.

\section{References}

1. Attaran, M. The Impact of 5G on the Evolution of Intelligent Automation and Industry Digitization. J. Ambient Intell. Hum. Comput. 2021. [CrossRef] [PubMed]

2. Chang, Y.; Deng, L.; Meng, X.; Zhang, W.; Wang, C.; Wang, Y.; Zhao, S.; Lin, L.; Crittenden, J.C. Closed-Loop Electrochemical Recycling of Spent Copper(II) from Etchant Wastewater Using a Carbon Nanotube Modified Graphite Felt Anode. Environ. Sci. Technol. 2018, 52, 5940-5948. [CrossRef] [PubMed]

3. Arya, S.; Patel, A.; Kumar, S.; Pau-Loke, S. Urban Mining of Obsolete Computers by Manual Dismantling and Waste Printed Circuit Boards by Chemical Leaching and Toxicity Assessment of Its Waste Residues. Environ. Pollut. 2021, 283, 117033. [CrossRef] [PubMed]

4. Rajahalme, J.; Perämäki, S.; Budhathoki, R.; Väisänen, A. Effective Recovery Process of Copper from Waste Printed Circuit Boards Utilizing Recycling of Leachate. JOM 2021, 73, 980-987. [CrossRef]

5. Gu, M.; Li, X.; Lin, M.; Jiao, S.; Hunag, W.; Zhang, J.; Wang, Y.; Zhang, H.; Zhao, Z. Research on copper-containing etching waste liquid disposal and management countermeasures in Jiangsu Province. J. Environ. Eng. Technol. 2018, 8, $200-204$. 
6. Xu, T.; Wang, L.; Wang, X.; Li, T.; Zhan, X. Heavy Metal Pollution of Oil-Based Drill Cuttings at a Shale Gas Drilling Field in Chongqing, China: A Human Health Risk Assessment for the Workers. Ecotoxicol. Environ. Saf. 2018, 165, 160-163. [CrossRef] [PubMed]

7. Heidari, M.; Darijani, T.; Alipour, V. Heavy Metal Pollution of Road Dust in a City and Its Highly Polluted Suburb; Quantitative Source Apportionment and Source-Specific Ecological and Health Risk Assessment. Chemosphere 2021, 273, 129656. [CrossRef] [PubMed]

8. Qing, X.; Yutong, Z.; Shenggao, L. Assessment of Heavy Metal Pollution and Human Health Risk in Urban Soils of Steel Industrial City (Anshan), Liaoning, Northeast China. Ecotoxicol. Environ. Saf. 2015, 120, 377-385. [CrossRef] [PubMed]

9. Nayak, A.K.; Raja, R.; Rao, K.S.; Shukla, A.K.; Mohanty, S.; Shahid, M.; Tripathi, R.; Panda, B.B.; Bhattacharyya, P.; Kumar, A.; et al. Effect of Fly Ash Application on Soil Microbial Response and Heavy Metal Accumulation in Soil and Rice Plant. Ecotoxicol. Environ. Saf. 2015, 114, 257-262. [CrossRef] [PubMed]

10. Qin, G.; Niu, Z.; Yu, J.; Li, Z.; Ma, J.; Xiang, P. Soil Heavy Metal Pollution and Food Safety in China: Effects, Sources and Removing Technology. Chemosphere 2021, 267, 129205. [CrossRef] [PubMed]

11. Li, Z.; Ma, Z.; van der Kuijp, T.J.; Yuan, Z.; Huang, L. A Review of Soil Heavy Metal Pollution from Mines in China: Pollution and Health Risk Assessment. Sci. Total Environ. 2014, 468-469, 843-853. [CrossRef] [PubMed]

12. Senila, M.; Cadar, O.; Senila, L.; Hoaghia, A.; Miu, I. Mercury Determination in Natural Zeolites by Thermal Decomposition Atomic Absorption Spectrometry: Method Validation in Compliance with Requirements for Use as Dietary Supplements. Molecules 2019, 24, 4023. [CrossRef] [PubMed]

13. Senila, M.; Covaci, E.; Cadar, O.; Ponta, M.; Frentiu, M.; Frentiu, T. Mercury Speciation in Fish Tissue by Eco-Scale Thermal Decomposition Atomic Absorption Spectrometry: Method Validation and Risk Exposure to Methylmercury. Chem. Pap. 2018, 72, 441-448. [CrossRef]

14. Yang, H.; Wang, F.; Yu, J.; Huang, K.; Zhang, H.; Fu, Z. An Improved Weighted Index for the Assessment of Heavy Metal Pollution in Soils in Zhejiang, China. Environ. Res. 2021, 192, 110246. [CrossRef] [PubMed]

15. Chonokhuu, S.; Batbold, C.; Chuluunpurev, B.; Battsengel, E.; Dorjsuren, B.; Byambaa, B. Contamination and Health Risk Assessment of Heavy Metals in the Soil of Major Cities in Mongolia. Int. J. Environ. Res. Public Health 2019, 16, 2552. [CrossRef] [PubMed]

16. Shao, T.; Pan, L.; Chen, Z.; Wang, R.; Li, W.; Qin, Q.; He, Y. Content of Heavy Metal in the Dust of Leisure Squares and Its Health Risk Assessment-A Case Study of Yanta District in Xi'an. Int. J. Environ. Res. Public Health 2018, 15, 394. [CrossRef] [PubMed]

17. Doležalová Weissmannová, H.; Mihočová, S.; Chovanec, P.; Pavlovský, J. Potential Ecological Risk and Human Health Risk Assessment of Heavy Metal Pollution in Industrial Affected Soils by Coal Mining and Metallurgy in Ostrava, Czech Republic. Int. J. Environ. Res. Public Health 2019, 16, 4495. [CrossRef] [PubMed]

18. Sharafi, K.; Yunesian, M.; Nodehi, R.N.; Mahvi, A.H.; Pirsaheb, M. A Systematic Literature Review for Some Toxic Metals in Widely Consumed Rice Types (Domestic and Imported) in Iran: Human Health Risk Assessment, Uncertainty and Sensitivity Analysis. Ecotoxicol. Environ. Saf. 2019, 176, 64-75. [CrossRef] [PubMed] 